\title{
Home treatments with antipyretics and antimalarials given to underfives with fever in Mwanza, north-western Tanzania
}

\author{
HUMPHREY D. MAZIGO ${ }^{*}$, HADIJA M. BUSHAHU1, BENSON R. KIDENYAㄹ, EMMANUELA \\ E. AMBROSE ${ }^{1}$, MARIA ZINGA ${ }^{1}$ and JORG HEUKELBACH ${ }^{2}$ \\ ${ }^{1}$ Weill-Bugando University College of Health Sciences, P.O. Box 1464, Mwanza, Tanzania \\ ${ }^{2}$ Department of Community Health, School of Medicine, Federal University of Ceará, Fortaleza, Brazil
}

\begin{abstract}
Early diagnosis and prompt treatment is the recommended management for febrile illness among underfives. However, improper home management may be the cause of delay in seeking professional health care. This cross-sectional study was conducted at the outpatient department of Buzuruga Health Centre in Mwanza, Tanzania and involved 372 children $<5$ years of age. Socio-demographic data of caregivers and children, type and source of treatment, and duration of fever were recorded. A total of 283 (76.1\%) febrile underfives had received different types of treatment at home, before presenting at the hospital. The majority received antipyretics $(204 ; 72.1 \%)$, and only a few $(31 ; 10.9 \%)$ received antimalarials. The major sources of drugs were local drug stores $(270 ; 94.7 \%)$. Duration of fever $>1$ day (OR=2.69; 95\% CI: 1.95-3.70; $P<0.001)$, low grade fever $(\mathrm{OR}=4.37,95 \% \mathrm{CI}: 2.60-7.35 ; P<0.001)$ and fever accompanied with other major complaints $(\mathrm{OR}=1.14,95 \% \mathrm{CI}: 1.05-1.23 ; P=0.002)$ were significantly associated with prompt home medication before presenting to the health centre. In logistic regression analysis, duration of fever, low-grade fever and the presence of other symptoms remained significant predictors to receive antimalarial and or antipyretic drugs. In conclusion, home treatments with antipyretics and antimalarials in preschool children are common in Mwanza. Management of fevers may be improved by educating caregivers on community standard case definition of malaria while emphasizing the importance of early seeking of health facility services.
\end{abstract}

Keywords: Home treatment, fever, underfives, northwest Tanzania

\section{Introduction}

The clinical diagnosis of febrile diseases is difficult in sub-Saharan Africa, where multiple pathogens cause similar signs and symptoms (Akpede et al., 1992; Richens et al., 1992; Rooth et al., 1992; O'Dempsey et al., 1993; Olaleye et al., 1998). An estimated 870 million episodes of fever among African children occur each year (Snow et al., 2003). In malaria-endemic regions, these febrile episodes are usually considered by health professional or parents/guardians as malaria without further diagnostic approaches, especially in young children (Akpede et al., 1992; Richens et al., 1992; Rooth et al., 1992; O'Dempsey et al., 1993; Olaleye et al., 1998).

In fact, fever has been used as a rapid diagnostic tool for malaria due to its high sensitivity; specificity, though, is rather low (Chandramohan et al., 2002). In many of the health facilities where laboratory facilities are either available or not, the presence of fever is used as the entry point for presumptive diagnosis and treatment of malaria in

* Correspondence: Dr. Humphrey D. Mazigo: E-mail: $\underline{\text { humphreymazigo@bugando.ac.tz }}$ 
children. The situation is similar in communities living in holoendemic areas for malaria (Tarimo et al., 1998, 2000).

Caregivers (especially mothers) recognize fever as an early sign of malaria and have demonstrated a high level of awareness of this (Tarimo et al., 1998, 2000; Thera et al., 2000; Hamel et al., 2001). This ability of mothers or caregivers to suspect malaria in the presence of fever has resulted into early initiation of treatment in areas with difficult access to health facilities (Mwenesi et al., 1995; Ruebush et al., 1995). Prompt treatment outside the health facilities may serve in reducing disease-specific mortality in the underfives, but on the other hand it may also lead to incorrect diagnosis, and administration of inappropriate dosages and drugs, in the case of persisting fever (Thera et al., 2000). Another consequence is a possible delay in seeking appropriate diagnosis and treatment. This may have severe implications for diseases like P. falciparum malaria in which late diagnosis and therapy can lead to cerebral forms of the disease and high case fatality rates in underfives. The present study was therefore conducted to determine the types and sources of treatment, duration of febrile illness and factors associated with prompt treatment at home for young children with fever in Mwanza, north-western Tanzania.

\section{Material and Methods}

\section{Study area and population}

The study was conducted at the outpatient department of Buzuruga Health Centre, located in Mwanza City, north-western Tanzania. Mwanza City is located between latitudes $2^{\circ} 15^{\prime}-2^{\circ} 45^{\prime} \mathrm{S}$ and longitudes $32^{\circ} 45^{\prime}-45^{\circ} 38^{\prime} \mathrm{E}$ and lies at an altitude of $1140 \mathrm{~m}$. The study population included caregivers (parents/guardians) with under five year-old children attended at the outpatient department of Buzuruga Health Centre with a chief complaint of fever (defined as temperature $>37.5^{\circ} \mathrm{C}$ ).

\section{Study design and data collection}

This was a cross-sectional study conducted between August and October 2010. A sample of under five year-old children was clinically examined and body temperature taken using a clinical thermometer. A semi-structured questionnaire was administered to caregivers (parents/guardians) and the information collected included the caregiver's demographic information, child age and sex, duration of fever, and type and source of treatment. To minimize bias of collecting information from caregivers, only one doctor conducted the clinical examination and administered the structured questionnaire.

\section{Ethical considerations}

The study was conducted using protocol approved by the Faculty of Medicine, WeillBugando University College of Health Sciences, Mwanza, Tanzania. Permission to conduct the study at the Health Centre was sought from the Mwanza Regional Medical Officer and Mwanza Regional Administrative Secretary. Written consent to participate in the study was obtained from caregivers. 


\section{Data analysis}

Data were double entered in Microsoft Excel data sheets, cross-checked and transferred to and analysed using Stata version 11 (Stata Corp, College station, Texas, USA). Descriptive statistics were carried out to measure relative frequencies, percentages, and means of the variables. Bivariate analysis was carried out on variables being possible predictors of home medication. All factors with $P$-value $<0.2$ were retained for multivariate logistic regression and adjusted for age and sex.

\section{Results}

A total of 372 parents/guardians responded to the administered questionnaires; this included 370 (99.5\%) females and $2(0.5 \%)$ males. Of the 372 under five year-old children observed in the health centre, 196 (52.7\%) were males and 176 (47.3\%) females. The mean age of the children was $24.7 \pm 15.3$ months (range: 1 - 60). The most common complaint was fever only which accounted for $72.6 \%$ of the responses.

Table 1: Major complaints presented by underfives with fever $(n=372)$.

\begin{tabular}{lll}
\hline Symptoms/signs & Number & Percentage \\
\hline Only fever & 270 & 72.6 \\
Fever and cough & 23 & 6.2 \\
Fever and diarrhoea & 22 & 5.9 \\
Fever and vomiting & 21 & 5.7 \\
Fever and cold & 12 & 3.2 \\
Fever and body weakness & 8 & 2.2 \\
Fever and difficult breathing & 4 & 1.1 \\
Fever and loss of appetite & 4 & 1.1 \\
Fever and rashes & 2 & 0.5 \\
Fever and abdominal fullness & 1 & 0.3 \\
Fever and chest tightness & 1 & 0.3 \\
Fever and confusion & 1 & 0.3 \\
Fever + vomiting + diarrhoea & 1 & 0.3 \\
Fever + cough + vomiting & 1 & 0.3 \\
Fever + cold + cough & 1 & 0.3 \\
Total & 372 & $\mathbf{1 0 0}$ \\
\hline
\end{tabular}

The majority of parents/guardians $(365 ; 98.2 \%)$ had attained primary school education while only $7(1.9 \%)$ had secondary school education. A total of $227(61.0 \%)$ of the parents/guardians had between 1-3 children while 145 (39.0\%) had more than three children. Of the total, of 372 parents/guardians, 265 (69.6\%) were housewives.

A total of 207 (55.6\%) febrile children had remained with fever for 1-2 days at home before presented to Buzuruga Health Centre, while 165 (44.4\%) presented with fever for more than two days. The majority $(283 ; 76.1 \%)$ of the febrile children received different types of treatment for febrile illness at home before presenting to Buzuruga health centre. Of the children who received treatment at home, 204 (72.1\%) received nonsteroidal antipyretics (mainly Paracetamol) (Table 2). The antimalarials commonly used 
included amodiaquine, quinine and artemether+lumefantrine. Cloxacillin, erythromycin and trimethoprim-sulfamethoxazole were the most frequently used antimicrobials. The major sources of treatment were the local medical drug stores 270 (94.7\%), commonly referred as "duka la dawa baridi".

Table 2: Type and source of drugs administered to underfives children $(n=283)$ before presenting to health facility

\begin{tabular}{lll}
\hline Variable & $\mathbf{N}$ & $\mathbf{\%}$ \\
\hline Type of drug & & \\
Non-steroidal antipyretics & 204 & 72.1 \\
Antimalarials & 31 & 10.9 \\
Herbal concoctions & 18 & 6.4 \\
Antimicrobials & 12 & 4.2 \\
Cough syrup + analgesics & 6 & 2.1 \\
Oral dehydrations + analgesics & 5 & 1.8 \\
Oral dehydration & 4 & 1.4 \\
Diazepam & 3 & 1.1 \\
Source of drugs & & \\
Drug store & 270 & 94.7 \\
Herbal drugs at home & 10 & 3.51 \\
Home (drugs remained at home) & 4 & 1.4 \\
Traditional healers & 1 & 0.35 \\
\hline
\end{tabular}

In logistic regression analysis, duration of fever of more than one day, low grade fever (body temperature $37.5^{\circ} \mathrm{C}-37.9^{\circ} \mathrm{C}$ ) and having fever with other symptoms were significant predictors in children $<5$ years of age to receive drugs at home before presenting to the health centre (Table 3).

Table 3: Multivariate logistic regression to determine the predictors of using drugs before presentation of febrile underfives

\begin{tabular}{|c|c|c|c|c|c|c|}
\hline \multirow[t]{2}{*}{ Variable } & \multicolumn{3}{|c|}{ Unadjusted } & \multicolumn{3}{|c|}{ Adjusted } \\
\hline & OR & $95 \%$ CI & $P$ value & $\mathrm{OR}^{*}$ & $95 \%$ CI & $P$ value \\
\hline Duration of fever $>1$ day & 2.69 & $1.95-3.70$ & $<0.001$ & 2.33 & $1.68-3.24$ & $<0.001$ \\
\hline $\begin{array}{l}\text { Presence of other major } \\
\text { complaints }\end{array}$ & 1.14 & $1.05-1.23$ & 0.002 & 1.16 & $1.06-1.26$ & $<0.001$ \\
\hline Low grade fever & 4.37 & $2.60-7.35$ & $<0.001$ & 3.56 & $2.00-6.31$ & 0.001 \\
\hline Male sex & 0.83 & $0.51-1.34$ & 0.45 & 0.79 & $0.45-1.36$ & 0.39 \\
\hline Age (months) & 0.99 & $0.98-1.01$ & 0.46 & 0.97 & $0.97-1.09$ & 0.31 \\
\hline
\end{tabular}

*Complaints/symptoms - fever alone versus fever with other symptoms

\section{Discussion}

The present study shows that pre-hospital antimalarial treatment of febrile children remains a significant practice among caregivers of children $(<5$ years $)$ in the study area, mainly in the case of low fever. This was consistent with previous studies, which reported that the majority of underfives received treatment outside health facilities 
(Slutsket et al., 1994; Mwenesi et al., 1995; Ruebush et al., 1995; Tarimo et al., 1998, 2000; Emeka, 2005). The major complaints were fever and most of the children $(55.6 \%)$ remained with fever for two days or less without attending health facilities. In Ethiopia, $52.3 \%$ of the caregivers reported to have initiated treatment to febrile patients within two days of the onset of fever (Sauerborn et al., 1989). In malaria-endemic areas, fever is normally related to malaria and for effective treatment and control of malaria; prompt access to early diagnosis and effective antimalarial treatment is one of the major strategies for reducing morbidity and mortality from malaria (Gove, 1997). Thus, delay in presentation of underfives with febrile illness may result in severe health consequences associated with disease in question and sometimes can lead to a high case fatality.

In Sub-Saharan Africa, the lack of access to health care facilities and inability to pay for hospital bills cause many residents receiving their initial treatment for febrile illnesses at home using herbal medicines, oral antipyretics or antimalarial drugs purchased without prescription in local shops (Raynal, 1985; Kaseje et al., 1987; Glik et al., 1989; Gove et al., 1997). Many patients only visit a health centre or hospital after the illness has failed to respond to several days of self-treatment (Sauerborn et al., 1989). However, in Tanzania underfive year-old children are entitled for free treatment. In the present study, more than three quarters of the febrile children visited a health centre after taking medication at home. Only about a quarter of the underfives sought treatment from health facilities for febrile illness without home medication. Similar observations have also been reported from other studies elsewhere (Deming et al., 1987; Mwenesi et al., 1995; Ruebush et al., 1995; Emeka, 2005).

Antipyretics were the most frequently used drugs for home treatment of fever. The reason for the low use of antimalarials before seeking medical care at health facility could not be established. It is most probably due to the fact that antimalarials are obtained at health facility free of charge and that antimalarials such as artemisinin combination are expensive. The urban setting of the study area may have accounted for the low use of traditional or herbal drugs. However, poor access to formal health services, inadequate services (drug stock-out and long waiting time), and the easy availability of over-the-counter treatments encourage the purchase of antipyretic and antimalarial drugs from unofficial sectors (Raynal, 1985; Hamel et al., 2001). Antimalarials and antipyretics do not need mandatory prescriptions in Tanzania, and people obtain them easily from pharmacies and drug stores. This suggests a common practice of self-treatment of fever and/or malaria without prescription in our study population.

Home management of children illnesses with antimalarials have been reported in studies in Mali and Nigeria (Thera et al., 2000; Fawole and Onadeko et al., 2001). The use of antipyretics and antimalarials as the initial treatment probably is a reasonable approach for the first 12-24 hours, since recovery from many febrile illnesses occurs spontaneously, but caregivers should understand that the complications of $P$. falciparum malaria can develop very rapidly and that they should seek prompt and proper treatment from health professionals. The main disadvantage of home medication is the 
lack of clinical evaluation of the patients by trained health professionals, which could result in missed alternative diagnoses and delay in appropriate treatment (Hamel et al., 2001). The promotion of drug-resistant $P$. falciparum because of the widespread use of antimalarials in cases of under dosing and the risks associated with potentially toxic doses of these drugs are other possible disadvantages.

Several factors have been reported to be associated with prompt medication at home in underfives (Deresa et al., 2003; Temu et al., 2006). In the present study, duration of fever of more than one day, low grade fever and having fever accompanied with other symptoms/signs were significantly associated with prompt home medication to underfives with febrile illness. Similar observations have been reported in Ethiopia (Sauerborn et al., 1989). The observed factors support the recommendations proposed by the Integrated Management of Childhood Illnesses strategy (Sauerborn et al., 1989; Gove, 1997). However, since some studies have shown that that early treatment of childhood fever with ineffective drugs may results into severe outcomes (Orimadegun et al., 2008) it is important to emphasize that in the case of persisting fever, caregivers should seek health services in time, for proper diagnosis and management.

It can be concluded that the majority of children received pre-hospital treatment at home, and that local drug stores are the major sources of the drugs. Home-based management of fever may be a hindrance to prompt access to effective treatment because of the delay in seeking proper care. In addition to health education regarding signs and symptoms of malaria, focusing on caregivers, training of drug shop owners or shop keepers as a channel for information to the community may have significant impact in offering proper use of drugs. Management of fever can also be improved by educating caregivers/guardians on the importance of early seeking hospital services for persisting fevers.

\section{Competing interests}

The authors declare that they have no competing interests.

\section{Acknowledgements}

We acknowledge the valuable cooperation of caregivers to accept to participate in the study and their children. We also thank the Mwanza Region Medical Officer and Region Administrative Officer for giving permission to conduct this study at Buzuruga Health Centre.

\section{References}

Ajayi, I.O. \& Falade, C.O. (2006) Pre-hospital treatment of febrile illness in children attending the general outpatients clinic, University College Hospital, Ibadan, Nigeria. African Journal of Medical Science 35, 85-91. 
Akpede, G.O., Abiodun, P.O. \& Sykes, R.M. (1992) Relative contribution of bacteraemia and malaria to acute fever without localizing signs of infection in under-five children. Journal of Tropical Pediatrics 38, 295-298.

Chandramohan, D., Jaffar, S. \& Greenwood, B. (2002) Use of clinical algorithms for diagnosing malaria. Tropical Medicine and International Health 7, 45-52.

Deming, M.S., Gayibor, A., Murphy, K., Jones, T.S. \& Karsa, T. (1989) Home treatment of febrile children with antimalarial drugs in Togo. Bulletin of the World Health Organization 67, 695-700.

Deressa, W., Ali, A. \& Enqusellassie, F. (2003) Self-treatment of malaria in rural communities, Butajira, southern Ethiopia. Bulletin of the World Health Organization 81, 261-268.

Emeka N.C. (2005) Treatment received by under fives having fever before presenting at the children's outpatient clinic of a tertiary health facility in Owerri, Nigeria. Annals of African Medicine 4, 68 - 71.

Fawole, O.I. \& Onadeko, M.O. (2001) Knowledge and home management of malaria fever by mothers and care givers of under five children. West African Journal of Medicine 20,152-157.

Glik, D.C., Ward, W.B., Gordon, A. \& Haba, F. (1989) Malaria treatment practices among mothers in Guinea. Journal of Health and Social Behaviour 30, 421-435.

Gove, S. (1997). Integrated management of childhood illness by outpatient health workers: technical basis and overview. The WHO Working Group on Guidelines for Integrated Management of the Sick Child. Bulletin of the World Health Organization 75, 7-24.

Hamel, M.J., Odhacha, A., Roberts, J.M. \& Deming, M.S. (2001) Malaria control in Bungoma district, Kenya: a survey of home treatment of children with fever, bed net use and attendance at antenatal clinics. Bulletin of World Health Organization, 79, 1014-1023.

Kaseje, D.C., Spencer, H.C. \& Sempebwa, E.K. (1987) Usage of community-based chloroquine treatment for malaria in Saradidi, Kenya. Annals of Tropical Medicine and Parasitology 81, 111-115.

Mwenesi, V.M., Harpham, T. \& Snow, R.W. (1995) Child malaria treatment practices among mothers in Kenya. Social Science and Medicine 40, 1271-1277.

O'Dempsey, T.J., McArdle, T.F., Laurence, B.E., Lamont, A.C., Todd, J.E. \& Greenwood, B.M. (1993) Overlap in the clinical features of pneumonia and malaria in African children. Transactions of the Royal Society of Tropical Medicine and Hygiene 87, 662665.

Olaleye, B.O., Williams, L.A., D'Alessandro, U., Weber, M.M., Mulholland, K., Okorie, C., Langerock, P., Bennett, S. \& Greenwood, B.M. (1998) Clinical predictors of malaria in Gambian children with fever or a history of fever. Transactions of the Royal Society of Tropical Medicine and Hygiene 92, 300-304.

Orimadegun, A.E., Amodu, O.K., Olumese, P.E. \& Omota, O.O. (2008) Early home treatment of childhood fevers with ineffective antimalarials is deleterious in the outcome of severe malaria. Malaria Journal 7:143. 
Raynal, A.L. (1985) Use of over-the-counter medications in rural Matabeleland, Zimbabwe: the case for upgrading the dispensing skills of rural shopkeepers. Central African Journal of Medicine 31, 92-97.

Richens, J., Smith, T., Mylius, T. \& Spooner, V. (1992) An algorithm for the clinical differentiation of malaria and typhoid: a preliminary communication. Postgraduate Medical Journal 35, 298-302.

Rooth, I. \& Bjorkman, A. (1992) Fever episodes in a holoendemic malaria area of Tanzania: parasitological and clinical findings and diagnostic aspects related to malaria. Transactions of the Royal Society of Tropical Medicine and Hygiene 86, 479482.

Ruebush, T.K., Kren, M.K., Campbell, C.C. \& Oloo, A.J. (1995) Self treatment of malaria in rural area of western Kenya. Bulletin of the World Health Organization 73, 229236.

Sauerborn, R., Nougtara, A. \& Diesfeld, H.J. (1989) Low utilization of community health workers: results from a household interview survey in Burkina Faso. Social Science and Medicine 29, 1163-1174.

Slutsker, L., Chitsulo, L., Macheso, A. \& Steketee, R.W. (1994) Treatment of malaria fever episodes among children in Malawi: results of KAP survey. Tropical Medicine and Parasitology 45, 61-64.

Snow, R.W., Eckert, E. \& Teklehaimanot, A. (2003) Estimating the needs for artesunatebased combination therapy for malaria case-management in Africa. Trends in Parasitology 19, 363-369.

Tarimo, D.S., Lwihula, G.K., Minjas, J.N. \& Bygbjerg, I.C. (2000) Mothers' perception and knowledge on childhood malaria in the holoendemic Kibaha district, Tanzania: implication for malaria control and the IMCI strategy. Tropical Medicine and International Health 5, 179-184.

Tarimo, D.S., Urassa, D.P. \& Msamanga, G.I. (1998) Caregiver's perception of clinical manifestations of childhood malaria in holoendemic rural communities in Tanzania. East African Medical Journal 75, 93-96.

Temu, M.J., Kaale, E. \& Marawiti, M. (2006) Storage of antimalarials at household level and associated factors in Kiromo ward, Bagamoyo Tanzania. African Health Sciences 6, 43-48.

Thera, M.A., D'Alessandro, U. \& Thiero, M. (2000) Child malaria treatment practices among mothers in the district of Yanfolia, Sikasso region, Mali. Tropical Medicine and International Health 5, 876-881. 